\title{
Estimation of Swertiamarin in Enicostemma Littorale and Marketed Formulations Using HPLC-UV Method
}

\author{
Prawez Alam ${ }^{1,2 \star}$, Mohammad $\mathrm{Ali}^{2}$, Rahul Singh ${ }^{3}$, Faiyaz Shakeel ${ }^{4}$
}

\author{
'Department of Pharmacognosy, College of Pharmacy, King Saud University, Riyadh, Saudai Arabia \\ 2Department of Pharmacognosy and Phytochemistry, Faculty of Pharmacy, Jamia Hamdard, New Delhi-110062, India \\ ${ }^{3}$ Herbal Drug Research (Analytical Development) Ranbaxy Research laboratories, Gurgaon, Haryana, India \\ ${ }^{4}$ Department of Pharmaceutics, Faculty of Pharmacy, Al-Arab Medical University, Benghazi-5341, Libya
}

\begin{abstract}
A simple, economic, reproducible, robust and precise HPLC method for estimation of swertiamarin in both 60 $\%$ methanolic extract of Enicostemma littorale and marketed formulations was developed and validated in present investigation. The mobile phase composed of methanol and water $(90: 10 \% \mathrm{v} / \mathrm{v})$, gave a sharp and well-defined peak of swertiamarin at the retention time of $10.15 \pm 1.52$ min. The limit of detection (LOD) and limit of quantification (LOQ) were 17.25 and $56.92 \mu \mathrm{g} / \mathrm{ml}$ respectively. The proposed method with high degree of precision and accuracy was employed for the estimation of swertiamarin in methanolic extract and in marketed formulation.
\end{abstract}

Keywords: Swertiamarin; HPLC; ICH guidelines; Enicostemma littorale

\section{Introduction}

Swertia Linn. (Gentianaceae) is an annual or perennial herb comprising more than 170 species among which 79 and 40 species are distributed in China and India respectively (Bhandari et al., 2006a). Approximately 20 species of this genus are used in Chinese traditional medicine to treat hepatic, choleric and antiinflammatory diseases (Bhandari et al., 2006a). Enicostemma littorale (Chota-Kirayat or Chota-Chirayata) is a glabrous perennial herb belongs to family Gentianaceae (Murali et al., 2002). It is a perennial herb attaining height of 15-20 inch with sessile lanceolate leaves and is found throughout India up to a height of $1500 \mathrm{ft}$ (Bhandari et al., 2006a). This plant has been widely used in traditional system of medicines for the treatment of diabetes, malaria and fewer (Maroo et al., 2003). This herb is also known for its anti-inflammatory effects (Sadique et al., 1987), anticancer activity (Kavimani and Manisenthlkumar, 2000), hypoglycemic, antioxidant and hypolipidemic potential in newly-diagnosed non-insulin-dependent diabetes mellitus (NIDDM) patients (Maroo et al., 2003). Its antidiabetic effects were also reported by other workers (Murali et al., 2002; Upadhyay and Goyal, 2004; Srinivasan et al., 2005). It is used as active ingredient in an antidiabetic herbomineral preparation (Murali et al., 2002; Babu and Prince, 2004). Recently aerial part of E. littorale was reported to show hypolipidaemic effect in $p$-dimethylaminobenzene (PDAB) induced hepatotoxic animasls (Gopal et al., 2004). A through literature survey has revealed that few analytical methods have been reported for the estimation of swertiamarin in plant, its extract and in formulations (Takie et al., 2001; Vishwakarama et al., 2004; Bhandari et al., 2006a; Bhandari et al., 2006b). Only two HPTLC methods are available for estima- tion of swertiamarin in E. littorale and its formulations (Vishwakarama et al., 2004; Bhandari et al., 2006b). Therefore the aim of present study was to develop a simple, economical, selective, precise, reproducible and robust high performance liquid chromatographic (HPLC) method for the estimation of swertiamarin in E. littorale, its extracts and in marketed formulation using UV detector. The proposed method was validated according to ICH guidelines (ICH, 1996).

\section{Experimental}

\section{Plant material and chemicals}

Enicostemma littorale (whole plant) was collected from three different geographical regions viz- Shivapuri (M.P), Ajmer (RAJ) in the month of February whereas sample from Haridwar (UA) was collected in the month of March. These plants were assigned batches like EL/SGTC/MP, EL/SSH/RAJ and EL/SSH/UA respectively in the samples obtained from M.P, Rajasthan and Uttaranchal (India). The identity of these batches was confirmed by taxonomist of Ranbaxy Research Laboratories, Gurgaon, India. The voucher specimen was deposited in Phytochemistry research laboratory, Jamia Hamdard (New Delhi), India. All the solvents were of HPLC grade and other chemicals used were of analytical reagent (AR) grade and obtained from E-Merck, Mumbai, India.

\section{Marketed formulations}

Two traditional ayurvedic marketed formulations A (tablet) and B (capsule) containing E. littorale extract was purchased from local market and used for quantification of swertiamarin.

\section{Preparation of sample solution}

About $5 \mathrm{~g}$ of the crude drugs weighed and refluxed with 100 $\mathrm{ml}$ of methanol for $1 \mathrm{~h}$ in water bath and filtered through whatmann filter paper (No. 41). The marc left out was refluxed again with $50 \mathrm{ml}$ of methanol for $1 \mathrm{~h}$ and filtered. The filtrates were combined and concentrated to $25 \mathrm{ml}$ in rotary vacuum evaporator (Medica Instrument Mfg. Co. Mumbai, India) to a

\footnotetext{
*Corresponding author: Dr Prawez Alam, Department of Pharmacognosy, College of Pharmacy, King Saud University, Riyadh, Saudi Arabia, Tel: +966-532771723; E-mail: prawez pharma@yahoo.com
}

Received December 06, 2009; Accepted December 21, 2009; Published December 21, 2009

Citation: Alam P, Ali M, Singh R, Shakeel F (2009) Estimation of Swertiamarin in Enicostemma Littorale and Marketed Formulations Using HPLC-UV Method. J Bioanal Biomed 1: 022-027. doi:10.4172/1948593X.1000005

Copyright: (c) 2009 Alam P, et al. This is an open-access article distributed under the terms of the Creative Commons Attribution License, which permits unrestricted use, distribution, and reproduction in any medium, provided the original author and source are credited.

J Bioanal Biomed 
Citation: Alam P, Ali M, Singh R, Shakeel F (2009) Estimation of Swertiamarin in Enicostemma Littorale and Marketed Formulations Using HPLC-UV Method. J Bioanal Biomed 1: 022-027. doi:10.4172/1948-593X.1000005

final volume of $25 \mathrm{ml}$. This solution was used as test solution in the HPLC analysis.

\section{Sample preparation for quantification of swertiamarin in marketed formulations}

6 tablets (formulation A) or 6 capsules (formulation B) were crushed and dissolved in $50 \mathrm{ml}$ of distilled water, transferred to a separating funnel. It was then extracted thrice with $140 \mathrm{ml}$ each of extraction media (chloroform: methanol: butanol-25:2:3). The organic layer was passed over anhydrous sodium sulphate and evaporated to dryness on water bath under vacuum. The residue left was reconstituted in $20 \mathrm{ml}$ of methanol, which was used as test solution in HPLC analysis.

\section{Preparation of standard solution}

Accurately weighed $10.2 \mathrm{mg}$ of swertiamarin (purity $98 \%$ ) reference standard was transferred to $25 \mathrm{ml}$ volumetric flask. Methanol was added and sonicated in ultrasonic water bath to dissolve. Volume was made up with methanol to $25 \mathrm{ml}$. This gives concentration of $399.84 \mu \mathrm{g} / \mathrm{ml}$. $10 \mathrm{ml}$ of this solution was further diluted to $13.32 \mathrm{ml}$ with methanol to get concentration of $300 \mu \mathrm{g} / \mathrm{ml}$ This solution was used as a reference solution (stock solution) for swertiamarin.

\section{Equipment and conditions}

A Shimadzu model HPLC equipped with quaternary LC-10A VP pumps, variable wavelength programmable UV/VIS detector SPD-10AVP column oven (Shimadzu), SCL 10AVP system controller (Shimadzu), Rheodyne injector fitted with a $20 \mu$ l loop and Class-VP 5.032 software was used. The chromatographic column used was a reverse phase $\mathrm{C} 18,250 \mathrm{X} 4.6 \mathrm{~mm}, 5 \mathrm{mic}$ Zorax RP-HPLC. The column and HPLC system were kept at ambient conditions. The mobile phase was Methanol: water (9:1) with the flow rate of $1.0 \mathrm{ml} / \mathrm{min}$. The injection volume was $20 \mu \mathrm{l}$ and the elutes were analyzed at a wavelength of $338 \mathrm{~nm}$.

\section{Method development}

Various solvent systems were tried for the development of a suitable HPLC method for estimation of swertiamarin in $60 \%$ methanolic extract and marketed formulations. Mobile phases tried for these purposes were methanol: water $(10: 90 \%)$, methanol: water (40:60\%), methanol: water $(90: 10 \%)$, acetonitrile: water $(10: 90 \%)$ acetonitrile: water $(40: 60 \%)$ and acetonitrile: water $(90: 10 \%)$. The suitability of the solvent system was decided by cost, sensitivity of the assay and time required for the analysis.

\section{Calibration curve of swertiamarin}

Various concentrations $(50-300 \mu \mathrm{g} / \mathrm{ml})$ were made for the preparation of calibration curve from the prepared standard stock solution. The mobile phase after filtration through $0.45 \mu \mathrm{m}$ membrane filter was delivered at $1.0 \mathrm{ml} / \mathrm{min}$ for column standardization. The baseline was continuously monitored during the column standardization. The wavelength of detection was selected at $338 \mathrm{~nm}$. The prepared dilutions (concentrations) were injected serially and areas under the peaks were recorded for each concentration. The stability of drug in solution during analysis was also determined by repeated analysis of samples during the course of experimentation on the same day and also after $48 \mathrm{~h}$ storage of drug solution at laboratory conditions and in the refrigerator.

\section{Method validation}

\section{Linearity}

The linearity of swertiamarin was checked between 50-300 $\mu \mathrm{g} / \mathrm{ml}$ concentration range. Graph was plotted between concentration and area for linearity.

\section{Accuracy as recovery}

Accuracy was determined as \% recovery by standard addition method. The preanalyzed sample of swertiamarin $(100 \mu \mathrm{g} / \mathrm{ml})$ was spiked with the extra $0,50,100$ and $150 \%$ of the standard swertiamarin and the mixtures were reanalyzed by the proposed method. The \% recovery and percent relative standard deviation (\% RSD) were calculated at each concentration level.

\section{Precision}

Precision was determined at two levels according to $\mathrm{ICH}$ guidelines (repeatability and intermediate precision). Repeatability was determined as intraday precision whereas intermediate precision was determined by carrying out inter-day variation for the determination of swertiamarin at four different concentration levels of $100,150,200$ and $250 \mu \mathrm{g} / \mathrm{ml}$ in triplicates.

\section{Reproducibility}

Reproducibility of the proposed method was checked by analyzing precision on a different instrument, which was analyzed by another person in different laboratory. Both intraday and intermediate precision was calculated at four different concentration levels of 100, 150, 200 and $250 \mu \mathrm{g} / \mathrm{ml}$ in triplicates.

\section{LOD and LOQ}

LOD and LOQ were determined by standard deviation (SD) method. LOD and LOQ were determined by injecting blank sample to the chromatograph in triplicates, peak area of this blank was recorded. LOD and LOQ were determined using the slope of the calibration curve and SD of the blank sample using following formulae:

$$
\begin{aligned}
& \mathrm{LOD}=3.3 \times \mathrm{SD} / \mathrm{S} \\
& \mathrm{LOQ}=10 \times \mathrm{SD} / \mathrm{S}
\end{aligned}
$$

Where SD is the standard deviation of the blank response and $\mathrm{S}$ is the slope of the calibration curve.

\section{Robustness}

Robustness of the method was determined by changing the flow rate $(1.1$ and $0.9 \mathrm{ml} / \mathrm{min})$ of mobile phase. The change in retention time $\left(\mathrm{R}_{\mathrm{t}}\right)$ was recorded and \% RSD was calculated.

\section{Quantification of swertiamarin in methanolic extract and formulations}

The test samples were injected and chromatograms were obtained in same conditions as that of standard swertiamarin. The peak area of the peak corresponding to the $R_{t}$ of standard swertiamarin was recorded and content of the same was calculated from the regression equation obtained from calibration curve.

\section{Results and Discussion}

\section{Method development}

The mobile phase composition was optimized to develop a 


\section{Journal of Bioanalysis \& Biomedicine - Open Access \\ JBABM/Vol.1 Issue 1}

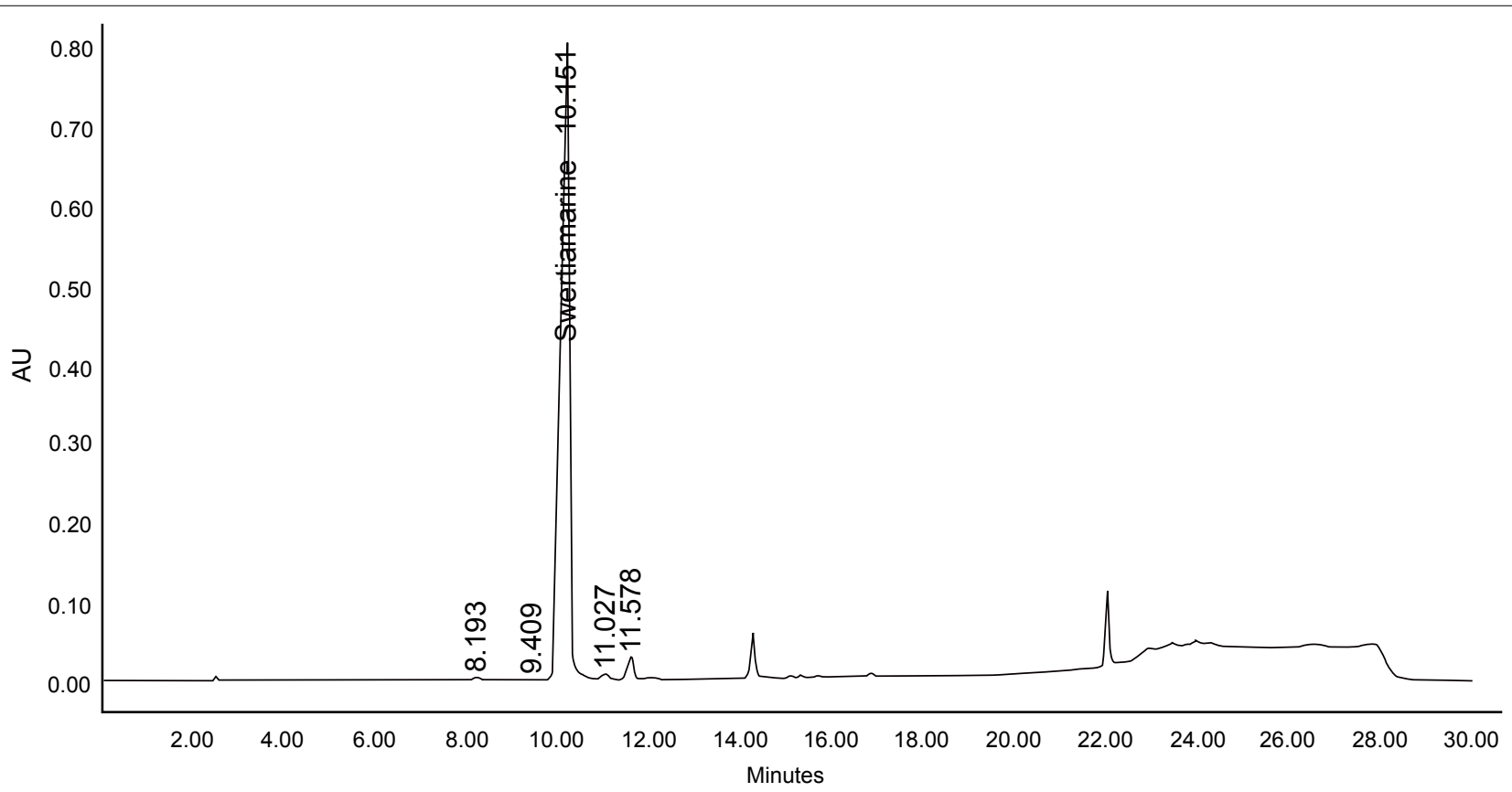

Figure 1: HPLC chromatogram of standard swertiamarin in methanol and water $(90: 10 \% \mathrm{v} / \mathrm{v})$ showing $\mathrm{R}_{\mathrm{t}}$ at $10.15 \mathrm{~min}$.

\begin{tabular}{|c|l|c|c|}
\hline Conc. $(\boldsymbol{\mu g} / \mathbf{m l})$ & Mean area $\mathbf{\pm S D}(\mathbf{n}=\mathbf{3})$ & \% RSD & Standard Error \\
\hline 50 & $1776453 \pm 1956$ & 1.10 & 1129 \\
\hline 75 & $2334156 \pm 9876$ & 0.42 & 5702 \\
\hline 100 & $3067541 \pm 16498$ & 0.53 & 9525 \\
\hline 150 & $4334512 \pm 15599$ & 0.35 & 8983 \\
\hline 200 & $5764123 \pm 27321$ & 0.47 & 15774 \\
\hline 250 & $6934561 \pm 48865$ & 0.70 & 28213 \\
\hline 300 & $8084151 \pm 59876$ & 0.74 & 34570 \\
\hline
\end{tabular}

Table 1: Calibration curve of swertiamarin in methanol: water (9:1) mixture.

suitable and accurate HPLC method for quantification of swertiamarin. Mobile phases tried for this purposes were methanol: water (90:10\%), acetonitrile: water $(25: 75 \%)$, methanol: water $(50: 50 \%)$, acetonitrile: water $(50: 50 \%)$ and acetonitrile: water $(75: 25 \%)$. The chromatogram obtained with methanol: water $(90: 10 \%)$ solvent system was found to have very good symmetry (1.15), with lowest $\mathrm{R}_{\mathrm{t}}(10.15 \mathrm{~min})$ and sharp well defined peak (Figure 1). Therefore the mixture of methanol: water (90:10\%) was optimized as the mobile phase. The drug was stable for a period of $48 \mathrm{~h}$ storage at laboratory temperature and under refrigerator temperature in methanol: water $(90: 10 \%)$ mixture.

\section{Calibration curve}

The calibration curve area versus concentration $(\mu \mathrm{g} / \mathrm{ml})$ was found linear in the range of $50-300 \mu \mathrm{g} / \mathrm{ml}$. Values of mean area with corresponding concentration, their standard deviation, $\%$ RSD and standard error are shown in Table 1. Statistical calculations were done at $5 \%$ level of significance. One-way analysis of variance (ANOVA) statistical test was performed to compare these results. The linear regression data for the calibration curve showed a good linear relationship over the concentration ranges of $50-300 \mu \mathrm{g} / \mathrm{ml}$ with respect to peak area as shown in Table 2 . The correlation coefficient value $\left(\mathrm{R}^{2}\right)$ was highly significant (Table 2) $(\mathrm{p}<0.05)$. No significant differences were observed in the slope of standard curves $(\mathrm{p} \geq 0.05)$. The retention time and asymmetry factor were found to be $10.15 \pm 1.52 \mathrm{~min}$ and 1.15 \pm 0.16 respectively.

\section{Validation of the Method}

\section{Linearity}

The linearity range of swertiamarin was obtained as 50-300 $\mu \mathrm{g} / \mathrm{ml}$ as shown in Table 1 . The regression equation was $\mathrm{Y}=$ $25653 X+490912$ with correlation coefficient $\left(\mathrm{R}^{2}\right)$ of 0.998 (Table 2).

\section{Accuracy as recovery}

The accuracy of the proposed method was calculated by recovery analysis which afforded recovery of 99.16-99.89\% after spiking the additional standard drug solution to the previously analyzed test solution. The values of \% recovery, \% RSD and

\begin{tabular}{|l|l|}
\hline Linearity range $(\boldsymbol{\mu g} / \mathbf{m l})$ & $\mathbf{5 0 - 3 0 0}$ \\
\hline Regression equation & $\mathrm{Y}=25653 \mathrm{X}+490912$ \\
\hline Correlation coefficient & 0.998 \\
\hline Slope \pm SD & $25653 \pm 297.56$ \\
\hline Intercept \pm SD & $490912 \pm 564.25$ \\
\hline Slope without intercept \pm SD & $28022 \pm 321.43$ \\
\hline Standard error of slope & 171.80 \\
\hline Standard error of intercept & 325.77 \\
\hline 95\% confidence interval of slope & $26392.25-24913.75$ \\
\hline 95\% confidence interval of intercept & $492313.78-489510.22$ \\
\hline Bias of intercept & -0.0612 \\
\hline
\end{tabular}

Table 2: Linear regression data for the calibration curve $(n=3)$. 
Citation: Alam P, Ali M, Singh R, Shakeel F (2009) Estimation of Swertiamarin in Enicostemma Littorale and Marketed Formulations Using HPLC-UV Method. J Bioanal Biomed 1: 022-027. doi:10.4172/1948-593X.1000005

\begin{tabular}{|l|l|l|l|l|}
\hline Excess drug added to analyte $(\boldsymbol{\%})$ & Theoretical content $(\boldsymbol{\mu g} / \mathbf{m l})$ & Conc. Found $(\boldsymbol{\mu g} / \mathbf{m l}) \mathbf{\pm S D}$ & \% Recovery & \% RSD \\
\hline 0 & 100 & $98.89 \pm 1.98$ & 98.89 & 2.00 \\
\hline 50 & 150 & $149.10 \pm 2.96$ & 99.40 & 1.98 \\
\hline 100 & 200 & $198.32 \pm 3.76$ & 99.16 & 1.89 \\
\hline 150 & 250 & $248.95 \pm 4.93$ & 99.58 & 1.98 \\
\hline
\end{tabular}

Table 3: Accuracy of the proposed method $(n=3)$.

\begin{tabular}{|l|l|l|l|l|l|l|}
\hline \multirow{2}{*}{ Conc. $(\mu \mathbf{g} / \mathbf{m l})$} & \multicolumn{3}{|l|}{ Repeatability $($ Intraday precision) } & \multicolumn{3}{l|}{ Intermediate precision (Interday) } \\
\cline { 2 - 8 } & Mean area \pm SD $(\mathbf{n}=3)$ & $\begin{array}{l}\text { Standard } \\
\text { error }\end{array}$ & \% RSD & Mean area \pm SD $(\mathbf{n}=\mathbf{3})$ & $\begin{array}{l}\text { Standard } \\
\text { error }\end{array}$ & \% RSD \\
\hline 100 & $3023543 \pm 14123$ & 8154.15 & 0.46 & $2999265 \pm 13987$ & 8075.63 & 0.46 \\
\hline 150 & $4212653 \pm 13876$ & 8011.54 & 0.32 & $4198765 \pm 13654$ & 7883.37 & 0.32 \\
\hline 200 & $5732876 \pm 26987$ & 15581.40 & 0.47 & $5698987 \pm 26321$ & 15196.88 & 0.46 \\
\hline 250 & $6889765 \pm 47876$ & 27642.03 & 0.69 & $6835765 \pm 47234$ & 27271.36 & 0.69 \\
\hline
\end{tabular}

Table 4: Precision of the proposed method.

\begin{tabular}{|l|l|l|l|l|l|l|}
\hline \multirow{2}{*}{ Conc. $(\boldsymbol{\mu g} / \mathbf{m l})$} & \multicolumn{3}{|l|}{ Repeatability $($ Intraday precision) } & \multicolumn{2}{l|}{ Intermediate precision (Interday) } \\
\cline { 2 - 7 } & Mean area \pm SD $(\mathbf{n}=\mathbf{3})$ & $\begin{array}{l}\text { Standard } \\
\text { error }\end{array}$ & \% RSD & Mean area \pm SD $(\mathbf{n}=\mathbf{3})$ & $\begin{array}{l}\text { Standard } \\
\text { error }\end{array}$ & \% RSD \\
\hline 100 & $2987652 \pm 18765$ & 10834.29 & 0.62 & $2898793 \pm 19876$ & 11475.75 & 0.68 \\
\hline 150 & $4154327 \pm 19987$ & 11539.83 & 0.48 & $4076543 \pm 20876$ & 12053.11 & 0.51 \\
\hline 200 & $5598654 \pm 30987$ & 17890.87 & 0.55 & $5543217 \pm 31432$ & 18147.80 & 0.56 \\
\hline 250 & $6698764 \pm 52321$ & 30208.42 & 0.78 & $6643214 \pm 52873$ & 30527.13 & 0.79 \\
\hline
\end{tabular}

Table 5: Reproducibility of the proposed method.

\begin{tabular}{|c|c|c|c|c|c|c|c|}
\hline \multirow[t]{2}{*}{ Conc. $(\mu \mathrm{g} / \mathrm{ml})$} & \multicolumn{3}{|c|}{ Flow rate $(\mathrm{ml} / \mathrm{min})$} & \multirow[t]{2}{*}{ Mean area \pm SD $(n=3)$} & \multirow{2}{*}{$\begin{array}{l}\text { Standard } \\
\text { error }\end{array}$} & \multirow[t]{2}{*}{ \% RSD } & \multirow[t]{2}{*}{ Mean $R_{t} \pm S D(\min )$} \\
\hline & Original & Used & Level & & & & \\
\hline \multirow[b]{3}{*}{100} & \multirow[b]{3}{*}{1.0} & 0.9 & -0.10 & $2945387 \pm 24543$ & 14170.32 & 0.83 & $10.45 \pm 1.55$ \\
\hline & & 1.0 & 0 & $2989654 \pm 22387$ & 12925.51 & 0.74 & $10.25 \pm 1.21$ \\
\hline & & 1.1 & +0.10 & $3165873 \pm 29821$ & 17217.66 & 0.94 & $10.10 \pm 1.46$ \\
\hline
\end{tabular}

Table 6: Robustness of the method by changing flow rate.

standard error are shown in Table 3, which indicated the good accuracy of the proposed method.

\section{Precision}

Precision was considered repeatability (intraday precision) and intermediate precision. Results of repeatability and intermediate precision were expressed in terms of \% RSD and are shown in Table 4 . The low values of $\%$ RSD indicated the repeatability and intermediate precision of the proposed method.

\section{Reproducibility}

Reproducibility of the proposed method was checked by obtaining precision of the method in another laboratory using different instrument and analyzed by another person but in the same condition. Both intraday and interday precision was examined in labs. There were no significant differences observed in the \% RSD values of intraday and interday precision, which indicates the reproducibility of the method Table 5.

\section{LOD and LOQ}

LOD and LOQ of the proposed method were determined by the standard deviation method and were found to be 17.25 and $56.92 \mu \mathrm{g} / \mathrm{ml}$ respectively, which indicated that the proposed method can be used in wide range for detection and quantifica- tion of swertiamarin effectively.

\section{Robustness of the method}

Robustness was determined to evaluate the influence of small but deliberate variation in the chromatographic conditions for the determination of swertiamarin. There was no significant change in the $\mathrm{R}_{\mathrm{t}}$ of swertiamarin by changing the flow rate (Table 6 ). Low value of the \% RSD indicated the robustness of the method as shown in Table 6.

\section{Quantification of swertiamarin in extracts of E. littorale}

The peaks of swertiamarin from sample solution were identified by comparing their $\mathrm{R}_{\mathrm{t}}$ obtained from the peaks with those of standard. HPLC profile of the $60 \%$ methanolic extract of the $E$. littorale was developed through the same condition as estimation of standard swertiamarin ( $\mathrm{R}_{\mathrm{t}}$ value $10.15 \mathrm{~min}$ ). The $\mathrm{R}_{\mathrm{t}}$ value of swertiamarin was $10.17 \mathrm{~min}$ in extract as shown in Figure 2. Some other peaks were also obtained in extract at different values of $R_{t}$ because of presence of some impurities in the extract as shown in Figure 2. The peak purity of extract was confirmed by superimposing the peaks of standard and extract. It was observed that extract of $E$. littorale collected from UA zone showed good content of swertiamarin followed by samples from MP and RAJ regions. The swertiamarin was quantified in extract of $E$. 


\section{Journal of Bioanalysis \& Biomedicine - Open Access \\ JBABM/Vol.1 Issue 1}

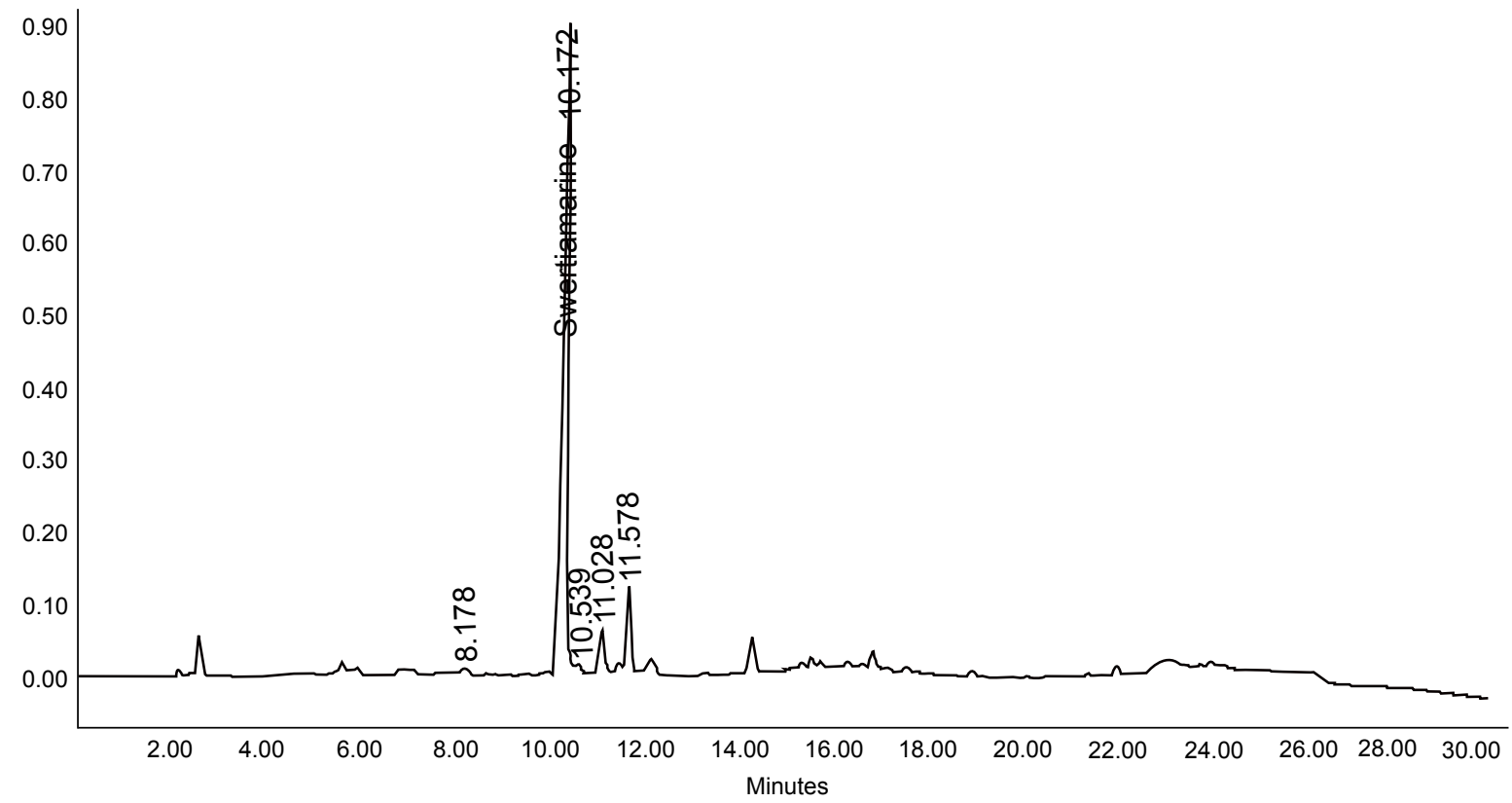

Figure 2: HPLC chromatogram of swertiamarin in $60 \%$ methanolic extract of Enicostemma littorale herb showing $\mathrm{R}_{\mathrm{t}}$ at 10.17 min.

littorale using regression equation and value was found to be $11.70 \%, 9.20 \%$ and $7.10 \%$ w/w in UA, MP and RAJ samples respectively.

\section{Quantification of swertiamarin in marketed formulations}

A single HPLC peak was observed at the same $\mathrm{R}$ in the samples of marketed formulations A and B. There was no interaction between the swertiamarin and other excipients present in the marketed formulations. The swertiamarin content was found to be $7.50 \%$ and $8.11 \% \mathrm{w} / \mathrm{w}$ in formulation $\mathrm{A}$ and $\mathrm{B}$ respectively. The value of $\%$ RSD was also too low which indicated the suitability of this method for the routine analysis of swertiamarin in marketed formulations.

\section{Applications}

The method was used to determine the presence swertiamarin in E. littorale from three different parts of the India. The swertiamarin was present in all the three extract and in marketed formulations, but there was considerable variation in the amounts present. It may be because of genetic variability, source of plant as well as external factors like seasonal and environmental variations, drying processes and storage conditions cannot be ruled out.

\section{Conclusions}

The proposed validated HPLC method is suitable for the quantification of swertiamarin in both methanolic extract and marketed formulations. Therefore, this method can be successfully used for the routine analysis of swertiamarin in both crude drugs and prepared formulations without any interference which can be explored for standardization and quality control of raw materials and marketed herbal products of traditional system of medicine containing E. littorale as an ingredient.

\section{Acknowledgement}

The authors are thankful to Ranbaxy Research Laboratory,
Gurgaon, India for providing facilities for completion of this research project.

\section{References}

1. Babu PS, Prince PSM (2004) Antihyperglycemic and antioxidant effects of hyponidd, an Ayurvedic herbomineral formulation on streptozocin induced diabetic rats. J Pharm Pharmacol 56: 1435-1442. » CrossRef » PubMed » Google Scholar

2. Bhandari P, Kumar N, Gupta AP, Singh B, Kaul VK (2006a) Micro-LC determination of swertiamarin in Swertia species and Bacoposie-A in Bacopa monnieri. Chromatogr 64: 599-602. » CrossRef » PubMed » Google Scholar

3. Bhandari P, Gupta AP, Singh B, Kaul VK (2006b) HPTLC determination of swertiamarin and amarogentin in Swertia species from the Western Himalayas. J Plan Chromatogr 19: 212-215. » CrossRef » PubMed » Google Scholar

4. Gopal R, Gnanamani A, Udayakumar R, Sadulla S (2004) Enicostemma littorale blume: A potential hypolipidemic plant. Natl Prod Rad 3: 401405. CrossRef » PubMed » Google Scholar

5. International Conference on Harmonisation (ICH) of Technical Requirements for Registration of Pharmaceuticals for Human Use: Harmonised Triplicate Guideline on Validation of Analytical Procedures: Methodology, Recommended for Adoption at Step 4 of the ICH Process on November 1996 by the ICH Steering Committee, IFPMA, Switzerland. »CrossRef » PubMed $\gg$ Google Scholar

6. Kavimani S, Manisenthlkumar KT (2000) Effects of methanolic extract of Enicostemma littorale on Dalton, s ascetic lymphoma. J Ethnopharmacol 71: 349-352. » CrossRef » PubMed » Google Scholar

7. Maroo J, Vasu VT, Gupta S (2003) Dose dependent hypoglycemic effects of aqueous extract of Enicostemma littorale blume in alloxan induced diabetic rats. Phytomed 10: 196-199. » CrossRef » PubMed » Google Scholar

8. Murali B, Upadhyaya UM, Goyal RK (2002) Effect of chronic treatment with Enicostemma littorale in non-insulin dependent diabetic (NIDD) rats. J Ethnopharmacol 81: 199-204. » CrossRef » PubMed » Google Scholar

9. Sadique J, Chandra T, Thenmozhi V, Elango V (1987) The anti-inflammatory effects of Enicostemma littorale and Mollugo cerviana. Biochem Med Metabol Biol 37: 167-176. » CrossRef » PubMed » Google Scholar

10. Srinivasan M, Padmanabhan M, Prince PSM (2005) Effects of aqueous Enicostemma littorale blume extract on key carbohydrate metabolic en- 
Citation: Alam P, Ali M, Singh R, Shakeel F (2009) Estimation of Swertiamarin in Enicostemma Littorale and Marketed Formulations Using HPLC-UV Method. J Bioanal Biomed 1: 022-027. doi:10.4172/1948-593X.1000005

zymes, lipid peroxides and antioxidants in alloxan induced diabetic rats. J Pharm Pharmacol 57: 497-503. » CrossRef » PubMed » Google Scholar

11. Takie H, Nakauchi K, Yoshizaki F (2001) Analysis of swertiamarin in Swertia herb and preparations containing this crude drug by capillary electrophoresis. Anal Sci 17: 885-888. » CrossRef » PubMed » Google Scholar

12. Upadhyay UM, Goyal RK (2004) Efficacy of Enicostemma littorale in type
2 diabetic patients. Phytother Res 18: 233-235. » CrossRef »PubMed » Google Scholar

13. Vishwakarma SL, Bagul MS, Rajani M, Goyal RK (2004) A sensitive HPTLC method for estimation of swertiamarin in Enicostemma littorale blume, Swertia chirata (wall) clarke and in formulations containing E. littorale. J Plan Chromatogr 17: 128-131. » CrossRef » PubMed » Google Scholar 